\title{
Relationship of Chronic LBP (Low Back Pain) with Hamstring Tightness in Professionals
}

\author{
Farwah Batool, Fatima Muaaz, Komal Tariq, Nazia Sarfraz
}

\begin{abstract}
OBJECTIVES: To find out the relationship between chronic LBP (Low back pain) and hamstring tightness in professionals.

METHODOLOGY: This was a cross sectional study. The sample size was 150 subjects. Data was collected from Allied Hospital and DHQ Hospital Faisalabad. Male and female both were selected who were High grade professionals (Engineer, Doctor, Businessman) Low grade professionals (Teacher, Bankers), House wife and house husband working in home or hotel. Oswestary disability questionnaire was used to determine the percentage disability in different professionals. Active Knee extension (AKE) test was used for hamstring tightness. Chi square test for independence is used to determine the relationship between chronic low back pain and hamstring tightness in professionals. SPSS was used for analysis of results.

RESULTS: About $28 \%(42)$ respondents with moderate disability have hamstring tightness and $19 \%(29)$ respondents with severe disability have hamstring tightness $(P=0.004)$. Disability percentage has relationship with activities of daily living. Subjects with active life style i.e. involve in different type of activities such as physical activity and exercise or physical work have tight hamstring $(P<0.003)$. Majority of housewife and house man have tight hamstring so chi square test shows that subject with different level of profession with back pain have hamstring tightness $(P<0.001)$.

CONCLUSION: Study indicates that subjects interlinked with different professions (High grade profession, Low grade profession, Housewife, house husband and peon, sweepers) with back pain have tight hamstring muscle. House wife and house husband are most commonly affected.
\end{abstract}

Key words: Chronic back pain, Hamstring tightness, Professionals

This article may be cited as: Batool F, Muaaz F, Tariq K, Sarfraz N. Relationship of Chronic LBP (Low Back Pain) with Hamstring Tightness in Professionals. J Liaquat Uni Med Health Sci. 2019;18(03):236-40. doi: 10.22442/jlumhs. 191830634

\section{INTRODUCTION}

Chronic pain is characterized by unpleasant physical sensations in one or more than one body region that remain beyond the three months and related with notable mental suffering or dysfunction result in limitation in daily life activities and social life ${ }^{1}$. Episode of low back pain are common between professionals ${ }^{2}$. Low back pain is the reason of worldwide disability as compared to any other condition and rank uppermost in case of disability (Years lived with disability -YLD) and $6^{\text {th }}$ in terms of overall burden DALY (Disability Adjusted Life Years) ${ }^{3}$. According to systematic review for the global burden of disease 2010 study, the worldwide point prevalence of low back pain was $9.4 \%$ and in some areas of the world as high as $15.0 \%$ (North Africa/ Middle East 14.8\%, Western Europe $15.0 \%)^{4}$. According to 2015 data, highest ratio of low back pain that result in activity limitation was $7.3 \%$ in Nordic Carolina. Mostly forty five million populations were influenced by low back pain. LBP is the major reason of dysfunction worldwide ${ }^{5}$. Epidemiological studies give essential information relating to many possibility factors of back pain, i.e. gender and age, occupation, body distribution, smoking addiction, life habits, economic status and social status ${ }^{6}$. Chronic low back pain is one of the mutual reasons of absenteeism from jobs. Teaching is a profession that is responsible for increased incidence of chronic LBP $^{6}$. LBP is a community health issue and is a frequently reason of work related problem between different professionals. ${ }^{7}$ Mechanical accident or danger in the different working area including hospital cause low back pain from lifting different things in different professionals ${ }^{8}$. Personal, physical, psychosocial risk factor and ergonomic stressors are all linked to work related back pain. Chronic low back pain is more common in teaching staff administration ${ }^{9}$. Mutual relationships, physical symptoms such as pain, fatigue, problems functioning, all are psychosocial factors that causes low back pain in professionals or limit their activities ${ }^{10}$. Long standing, incorrect back posture, psychosocial issues, rhythmic movements for prolonged period, repeated heavy weight carrying all causes decreased life quality as well as occurrence of 
chronic LBP ${ }^{10}$. Pain worsen due to prolonged standing specifically in persons who previously have back pain because in these individual's pattern of activation of low back muscles is altered owing to the activation of pain and spasm cycle ${ }^{11}$. Over utilization of body parts, abnormal posture, height, sex, weight and high intensity of working, mental and emotional strain all these factors cause musculoskeletal disorder and low back pain ${ }^{12}$. Hamstring muscles in lumbar flexed position maintain the spinal curve. If hamstring muscles flexibility is limited it produced more flexion at the spinal level in the slumped sitting position which leads the LBP and sufficient injury ${ }^{13}$. Muscular endurance and power were found to be strongly related to chronicity of back pain ${ }^{14}$. Chronic LBP is most frequently reason of absence from work, people are also in fear that if they do any activity or work it could cause back pain, so they prefer to do sick leave. Moreover, inactivity, people avoid exercise and other recreational activities due to the concern that it will lead to back pain and shortening of hamstring muscle. Chronic Low back pain has been become a common symptom and a major health concern in productive age for both males and females in developing countries. Work related characteristics may lead to wide range of musculoskeletal problems, particularly LBP. Many risk factors that cause back pain are mentioned in literature. Literature on hamstring flexibility that has linked to low back pain is not available in professionals. So, the purpose of this study was to determine whether hamstring tightness has linked with low back pain or not among different professionals.

\section{METHODOLOGY}

This was a cross sectional study. Purposive sampling was used for data collection. Total sample size was 150 subjects. Data was collected from DHQ Hospital and Allied hospital Faisalabad. Study was carried out from June-September 2017. All individuals of population belong to different professions had chronic low back pain were contacted for collection of data and for testing of hypothesis. Consent forms were signed from all subjects. Screening form filled by the individuals that were included in this study for maximum variable and factors which were needed for the result of this study Those individuals who did not fulfil the requirement of inclusive criteria were not included in this study. Age $>20$ years, chronic LBP subjects which last $>3$ months, both males and females that were belong to high grade professional, low grade profession, housewife, house husband and others (peon and sweepers), those females who were not pregnant and obese were considered in inclusion criteria. Those subjects above 55 years, less than 20 years, any systemic diseases or underlying pathology, any earlier history of operation, Acute LBP, pregnant females, psychological disorder, congenital deformity were excluded from study. All subjects completed the questionnaire and all scientific, medical terms were explained in a clear and simple way.

The primary outcome was chronic LBP the subjects who had back pain for last more than 3 months. A test was used to find out the hamstring muscle tightens which is known as Active Knee Extension ${ }^{15}$ and Oswestry LBP Disability Questionnaire (OLBPDQ) was used for LBP disability. This questionnaire indicates $0 \%$ to $20 \%$ is considered as minimal disability, $21 \%$ to $40 \%$ is considered moderate disability, $41 \%$ to $60 \%$ considered as severe disability, and $61 \%$ to $80 \%$ is considered as crippled and 81 to $100 \%$ is considered as complete disability/ bed bound $^{16}$. SPSS 24 was used for analysis of data ${ }^{17}$.

\section{RESULTS}

There were total 150 participants included in this study in which $65(43 \%)$ were males and $85(57 \%)$ were females. Basic characteristics of participants were shown in Table I. 106(71\%) subjects have hamstring tightness and $44(29 \%)$ have no hamstring tightness. Out of 150 subjects $14 \%$ (21) subjects had insignificant disability $(0 \%-20 \%), 28 \%$ (42) had moderate disability $(21 \%-40 \%), 19 \%(29)$ had severe disability $(41 \%-60 \%), 8 \%(12)$ had crippled disability $(61 \%-80 \%)$ and $1 \%$ (2) had complete disability (81\%-100\%) on Oswestry LBP (Low back pain) Disability questionnaire, as shown in Table II females were more affected with LBP disability than males. About $28 \%(42)$ subjects with moderate disability had hamstring tightness and $19 \%$ (29) subjects with severe disability had hamstring tightness so chi square test had showed the relationship between hamstring tightness and percentage disability in professionals (back pain score) $(p<0.004)$ Table II. Chi square test was applied to find out the relationship between hamstring muscles tightness and different activities of routine life, the $p$ values for hamstring muscle tightness and activities of daily living such as pain intensity, lifting, walking, sitting, standing, sleeping, personal care were less than selected alpha $(\alpha=0.05)$ which means that there was association between hamstring tightness and these activities of daily living except sex life, $(p=0.052)$ social life $(0.054)$ and travelling $(0.17)$ in professionals Table III. Forty seven percent (70) subjects with active life style had hamstring tightness and Twenty four percent (36) with sedentary life style had hamstring tightness so there was a significant relationship between hamstring tightness and life style of professionals Table IV. Five percent (7) subjects with high grade professional had 
Farwah Batool, Fatima Muaaz, Komal Tariq, Nazia Sarfraz

hamstring tightness, Fourteen percent (9) subject with low grade professional had hamstring tightness, Forty nine percent (74) house wife and house husband had hamstring tightness, Seven percent (11) subject with other professional had hamstring tightness therefore result showed that there was a relationship between hamstring tightness in individual with back pain and their professions shown in Table V.

TABLE I:

\section{BASIC CHARACTERISTICS OF PARTICIPANTS}

\begin{tabular}{|l|r|}
\hline Gender & \\
Male & $65(43 \%)$ \\
Female & $85(57 \%)$ \\
\hline Age & \\
25 or under & $19(12.7 \%)$ \\
$26-40$ & $62(41.3 \%)$ \\
$41-55$ & $68(45.3 \%)$ \\
\hline Life style & \\
Active & $109(72.7 \%)$ \\
Sedentary & $41(27.3 \%)$ \\
\hline Socioeconomic status & \\
Upper class & $14(9.3 \%)$ \\
Middle class & $82(54.7 \%)$ \\
Lower class & $52(34.7 \%)$ \\
\hline
\end{tabular}

TABLE IV: RELATIONSHIP BETWEEN HAMSTRING TIGHTNESS AND LIFE STYLE OF PATIENTS

\begin{tabular}{|l|r|r|r|r|}
\hline & \multicolumn{1}{|c|}{ Active } & Sedentary & Total & P value \\
\hline \begin{tabular}{l|r|r|r}
$|l|$ \\
Active knee extension test for hamstring \\
tightness
\end{tabular} & \multirow{2}{*}{ P $<0.003$} \\
\cline { 1 - 4 } Positive & $70(47 \%)$ & $36(24 \%)$ & $106(71 \%)$ & \\
\cline { 1 - 4 } Negative & $39(26 \%)$ & $05(3 \%)$ & $44(29 \%)$ & \\
\cline { 1 - 3 } Total & $109(73 \%)$ & $41(27 \%)$ & $150(100 \%)$ & \\
\hline
\end{tabular}

TABLE V: RELATIONSHIP BETWEEN

PROFESSION OF PATIENTS AND ACTIVE KNEE EXTENSION TEST FOR HAMSTRING TIGHTNESS

\begin{tabular}{|c|c|c|c|c|}
\hline & Positive & Negative & Total & $P$ value \\
\hline \multicolumn{4}{|c|}{ Profession of patients } & \multirow{6}{*}{$P<0.001$} \\
\hline $\begin{array}{l}\text { High Grade } \\
\text { Profession }\end{array}$ & $07(5 \%)$ & $04(3 \%)$ & $11(7 \%)$ & \\
\hline $\begin{array}{l}\text { Low Grade } \\
\text { Profession }\end{array}$ & $14(9 \%)$ & $14(9 \%)$ & $28(19 \%)$ & \\
\hline $\begin{array}{l}\text { House Wife / } \\
\text { House Husband }\end{array}$ & $74(49 \%)$ & $12(8 \%)$ & $86(57 \%)$ & \\
\hline Others & $11(7 \%)$ & $14(9 \%)$ & $25(17 \%)$ & \\
\hline Total & $106(71 \%)$ & $44(29 \%)$ & $\begin{array}{r}150 \\
(100 \%)\end{array}$ & \\
\hline
\end{tabular}

TABLE II: RELATIONSHIP BETWEEN HAMSTRING TIGHTNESS AND PERCENTAGE DISABILITY OF PATIENTS

\begin{tabular}{|c|c|c|c|c|c|c|c|}
\hline & $\begin{array}{l}\text { Insignificant } \\
\text { disability } \\
(0-20 \%)\end{array}$ & $\begin{array}{l}\text { Moderate } \\
\text { disability } \\
(21-40 \%)\end{array}$ & $\begin{array}{c}\text { Severe } \\
\text { disability } \\
(41-60 \%)\end{array}$ & $\begin{array}{l}\text { Crippled } \\
(61-80 \%)\end{array}$ & $\begin{array}{c}\text { Complete Severe } \\
\text { disability } \\
(81 \%-100 \%)\end{array}$ & Total & $P$ values \\
\hline \multicolumn{7}{|c|}{ Active knee extension test for hamstring tightness } & \multirow{4}{*}{$P<0.004$} \\
\hline Positive & $21(14 \%)$ & $42(28 \%)$ & $29(19 \%)$ & $12(8 \%)$ & $02(1 \%)$ & $106(71 \%)$ & \\
\hline Negative & $22(15 \% 0$ & $13(9 \%)$ & $05(3 \%)$ & $04(3 \%)$ & 0 & $44(29 \%)$ & \\
\hline Total & $43(29 \%)$ & $55(37 \%)$ & $34(23 \%)$ & $16(11 \%)$ & $02(1 \%)$ & $150(100 \%)$ & \\
\hline
\end{tabular}

TABLE III: DESCRIPTIVE STATISTICS FOR DIFFICULTY LEVEL OF DIFFERENT ACTIVITY OF DAILY LIVING

\begin{tabular}{|l|r|r|r|}
\hline \multicolumn{1}{|c|}{ Section names } & $\begin{array}{r}\text { Mean } \\
\text { score }\end{array}$ & $\begin{array}{r}\text { Standard } \\
\text { deviation }\end{array}$ & P value \\
\hline Pain intensity & 2.5 & 1.04 & 0.004 \\
\hline Personal care of patients & 2.67 & 1.13 & 0.058 \\
\hline Lifting & 3.58 & 1.49 & 0.02 \\
\hline Walking & 2.52 & 1.20 & 0.03 \\
\hline Sitting & 3.18 & 1.11 & 0.003 \\
\hline Standing & 3.36 & 1.23 & 0.003 \\
\hline Sleeping & 1.87 & 1.01 & 0.014 \\
\hline Sex life & 3.30 & 2.23 & 0.052 \\
\hline Social life & 2.73 & 1.33 & 0.054 \\
\hline Travelling & 2.90 & 1.23 & 0.17 \\
\hline
\end{tabular}

\section{DISCUSSION}

This study show that subjects of different professions had complaint of chronic back pain and their hamstring muscle were tightened. Housewives are usually affected with this condition. Life style commonly adopted lead to back pain and hamstring tightness. Activities of the daily living such as lifting walking etc. affect their hamstring muscles and causes back pain. Krol A $2017^{14}$ determined the relationship between mechanical factors and pelvic tilt in adults with and without LBP they were included total 60 female students where the average age was 22 years, the result of this study shows that subjects with or with pain vary in terms of age $P<0.001$. There was a significant relationship between pelvic tilt and 
LBP (R2=0.007 $\mathrm{P}=0.049)$ and lumber lordosis $(R 2=0.13 P=0.02)$. They also explained that position of pelvis depends on age, $\mathrm{Ml}$ and angle of lumber lordosis.

This current study result shows that chronic low back pain cause hamstring tightness in professionals $(P<0.004)$. Fasuyi FO $2017^{18}$ had evaluated the hamstring muscle length and pelvic tilt range between subject with or without LBP. The study involved the 30 subjects with LBP and 30 subjects without LBP. Subjects pelvic tilt range measured with digital inclinometer and hamstring tightness measured with active knee extension test. Subject without LBP had longer hamstring muscle length $(P=0.01)$ as compared to subjects with LBP. Pelvic tilt range was not different in both groups. Hamstring muscle length and pelvic tilt range had no correlation in subject with or with LBP. Pelvic tilt range was increases as hamstring. This current study showed that chronic low back pain had association with hamstring tightness $(P>0.004)$. Patel M $2018^{19}$ determine the trunk flexibility strength and endurance in physiotherapy student they indicate that mean of back extension range was $(3.52 \pm 1.19) \mathrm{cm}$ and back flexion range was $(6.84+1.54) \mathrm{cm}$. Median of manual muscle technique of upper back extensors was 4 lower back extensors was 3 upper back flexors was 4 and lower back flexor was 3 . Mean of back extensor endurance was $(93 \pm 46.01) \mathrm{sec}$ and mean of back flexor endurance was $(58.73 \pm 36.25)$ sec. Mean of left hamstring was $(150.94 \pm 13.4)$ degree and mean hamstring flexibility was $(149.59 \pm 13.81)$ degree.

Strength and hamstring flexibility were less in this student than normal. Trunk flexibility was normal. Endurance was below to average, and all these factors lead to back pain. This current study result showed that hamstring tightness was the cause of chronic low back pain and functional disability in professionals $(P<0.001)$. Arab AM 2014 ${ }^{20}$ had evaluated the effect of life style and working setting on hamstring length and lumbar lordosis in subject with or without pain. They were included 508 subjects. The result of this study showed no significant difference with life style and different work setting of subjects with or without back pain. Hamstring muscle length and lumbar lordosis both are not affected by life style and different work settings. This study indicates difference in hamstring muscle length and not shows significant difference in lumbar lordosis in individual with or without back pain. This study indicated that subject life style had also lead to hamstring tightness in chronic low back pain professionals $(P<0.003)$.

\section{CONCLUSION}

Current Study indicates that subject interlink with different professions (high grade profession, low grade profession, housewife, house husband and others i.e. peon and sweepers) with back pain have tight hamstring muscle. House wife or house husband are most commonly affected.

Further interventional study is necessary to manage the hamstring tightness in individuals with back pain. This research can be used at a government level to find out the quality of health of different individuals awareness to patients to save them from factors which caused chronic LBP and hamstring tightness.

Experimental studies should be conducted for the management of hamstring tightness in professionals.

Ethical permission: University of Faisalabad approval letter No. TUF/HOS/DPT/784 dated 10.10.2018.

Conflict of interest: There is no conflict of interest.

Funding: Authors have no funding / financial support from anyone.

\section{REFERENCES}

1. Nicholas $M$, Vlaeyen JW, Rief W, Barke A, Aziz Q, Benoliel R, et al. The IASP classification of chronic pain for ICD-11: Chronic Primary Pain. Pain. 2019; 160(1): 28-37. doi: 10.1097/j.pain. 0000000000001390.

2. Hoy D, Brooks P, Blyth F, Buchbinder R. The epidemiology of low back pain. Best Pract Res Clin Rheumatol. 2010; 24(6): 769-81. doi: 10.1016/j.berh.2010.10.002.

3. Hoy D, March L, Brooks P, Blyth F, Woolf A, Bain $C$, et al. The global burden of low back pain: estimates from the Global Burden of Disease 2010 study. Ann Rheum Dis. 2014; 73(6): 968-74. doi: 10.1136/annrheumdis-2013-204428.

4. Murray CJ, Vos $T$, Lozano R, Naghavi $M$, Flaxman AD, Michaud C, et al. Disability-adjusted life years (DALYs) for 291 diseases and injuries in 21 regions, 1990-2010: a systematic analysis for the Global Burden of Disease Study 2010. Lancet. 2012; 380(9859):2197-223. doi: 10.1016/S01406736(12)61689-4.

5. GBD 2015 Disease and Injury Incidence and Prevalence Collaborators. Global, regional, and national incidence, prevalence, and years lived with disability for 310 diseases and injuries, 19902015: a systematic analysis for the Global Burden of Disease Study 2015. Lancet. 2016; 388 (10053): 1545-602. doi: 10.1016/S0140-6736(16) 31678-6.

6. Yue P, Liu F, Li L. Neck/shoulder pain and low back pain among school teachers in China, prevalence and risk factors. BMC Public Health. 2012; 12: 789. doi: 10.1186/1471-2458-12-789.

7. Homaid MB, Abdelmoety D, Alshareef W, 
Alghamdi A, Alhozali $\mathrm{F}$, Alfahmi $\mathrm{N}$, et al. Prevalence and risk factors of low back pain among operation room staff at a Tertiary Care Center, Makkah, Saudi Arabia: a cross-sectional study. Ann Occup Environ Med. 2016; 28:1. doi:10.1186/s40557-016-0089-0

8. Lin HT, Hung WC, Hung JL, Wu PS, Liaw LJ, Chang $\mathrm{JH}$. Effects of Pilates on patients with chronic non-specific low back pain: a systematic review. J Phys Ther Sci. 2016; 28(10): 2961-9. doi:10.1589/jpts.28.2961.

9. Shafi M, Baloch S, Memon AS, Fatima H. Relationship amongst Job Stress and Chronic Back-Pain: A Cross-Sectional Study of Teaching and Administrative Staff. Conference: Annual International Conference on Qualitative and Quantitative Economics Research (QQE 2016). doi: 10.5176/2251-2012_QQE16.29

10. Yoshimoto T, Oka H, Katsuhira J, Fujii T, Masuda $\mathrm{K}$, Tanaka S, et al. Prognostic psychosocial factors for disabling low back pain in Japanese hospital workers. PloS One. 2017; 12(5): e0177908. doi: 10.1371/journal.pone.0177908.

11. Halim I, Omar A, Saman A, Othman I. Assesment of Muscle fatique associated with prolonged standing at work places. Saf Health Work. 2012; 3 (1): 31-42. doi:10.5491/SHAW.2012.3.1.31.

12. Cho K, Cho HY, Han GS. Risk factors associated with musculoskeletal symptoms in Korean dental practitioners. J Phys Ther Sci. 2016; 28(1): 56-62. doi: 10.1589/jpts.28.56.

13. Frey M, Poynter A, Younge K, De Carvalho D. The relationship between lumbopelvic flexibility and sitting posture in adult women. J Biomech.
2019; 84: 204-210. doi: 10.1016/j.jbiomech.2018. 12.048 .

14. Krol A, Polak M, Szczygiel E, Wojcik P, Gleb K. Relationship between mechanical factors and pelvic tilt in adults with and without low back pain. J Back Musculoskelet Rehabil. 2017; 30(4): 699705. doi: 10.3233/BMR-140177.

15. Neto T, Jacobsohn L, Carita AI, Oliveira R. Reliability of the active-knee-extension and straight-leg-raise tests in subjects with flexibility deficits. J Sport Rehabil. 2015; 24(4): pii. 20140222. doi: 10.1123/jsr.2014-0220.

16. Yates M, Shastri-Hurst N. The Oswestry disability index. Occup Med. 2017; 67(3): 241-2. doi:10.1093/occmed/kqw051.

17. IBM Corp. Released 2016. IMB SPSS Statistics for Windows, Version 24.0. Armonk, NY: IBM Corp.

18. Fasuyi FO, Fabunmi AA, Adegoke BOA. Hamstring muscle length and pelvic tilt range among individuals with and without low back pain. J Bodyw Mov Ther. 2017; 21(2): 246-250. doi: 10.1016/j.jbmt.2016.06.002.

19. Patel M, Sheth M. Trunk Flexibility strength and Endurance in Physiotherapy students - a cross sectional survey. Int J Sci Res. 2018; 7(4): 59-60. doi: 10.15373/22778179 .

20. Arab AM, Nourbakhsh MR. Hamstring muscle length and lumbar lordosis in subjects with different lifestyle and work setting: Comparison between individuals with and without chronic low back pain. J Back Musculoskelet Rehabil. 2014; 27(1): 63-70. doi: 10.3233/BMR-130420.

AUTHOR AFFILIATION:
Farwah Batool (Corresponding Author)
The University of Faisalabad
Institute of Physical Therapy
The University of Lahore, Punjab-Pakistan.
Email: farwahbatool6@gmail.com
Fatima Muaaz
The University of Faisalabad, Punjab-Pakistan.
Komal Tariq
The University of Faisalabad
Institute of Physical Therapy
The University of Lahore, Punjab-Pakistan.
Nazia Sarfraz
Assistant Professor
The University of Faisalabad, Punjab-Pakistan.

